\title{
Kasatkin Dmytro
}

Ph.D., head of department of computing system and network

National University of Biotechnology and Environmental Sciences of Ukraine, Kyiv, Ukraine

d.kasatkin@nubip.edu.ua

ORCID: 0000-0002-2642-8908

\section{Kasatkina Olga}

senior lecturer in Information Systems

National University of Biotechnology and Environmental Sciences of Ukraine, Kyiv, Ukraine

olga_kasat@ukr.net

\section{IMPLEMENTATION OF SPECIFIC DIDACTIC PRINCIPLES IN COMPUTER- ORIENTED LEARNING ENVIRONMENT}

\begin{abstract}
The article deals with the specific principles and specific features of perception of information in computer-oriented learning environment and peculiarities of the information assimilation, depending on the form of educational material presentation. We describe the psychological and physiological aspects of perception in the visualization of its submission. And as pointed out, process of perception of the information in computer-oriented learning environment is faster and easier. There is also outlined author's definition of the concept of computer-based learning environment, the system, which is an open education environment of the modern university.
\end{abstract}

Keywords: principle; information; multimedia; learning environment visualization; interactivity; e-environment

Relevance of the research. The emergence of multimedia allowed to reveal the fundamentally insurmountable flaw of a text based teaching materials, which is that they do not allow to use the huge reserves of performance of the human brain associated with its ability to speed processing of large volumes, panorama-perceived information posted in educational computer environments.

Analysis of previous studies. The notion of the learning environment is not new for educational researches (M. Basov, S. Shatskyi etc.). This concept fitted different meaning at different historical periods. S. Frene believed that learning environment serves as a field for various people activities, development of their creative skills, where man creates cultural values, exploring the real world in an atmosphere of freedom of choice and areas of knowledge of their interest. Modern educational theory does not share the views of S. Frene and A. Neil on the role of "free activities in the environment", but remain relevant to the person as a subject of activity that enriches the personal experience of the interaction with other objects the learning environment.

According to V. Krasylínikova, learning environment is a multifaceted, holistic, social and psychological reality that gives a person the material and spiritual conditions for its educational activities, sets the necessary psychological and pedagogical conditions, that provides immersion in the flow of targeted information and prepared ways of presenting the study, comprehensive personality development. As it was stated by S. Lobachev and V. Soldatkina, under the learning environment we understand a series of information resources, technology, education and the educational process, implemented within the framework of the common construction principles, that provides full cycle or logically completed part. By computer-oriented education environment, we understand a single information-educational space, based on the information integration of computer and telecommunication technologies (virtual library, distributed databases, optimally structured educational-methodical complex) and aimed at the self-development of personality in open education system of a modern university environment. 
Thus, the concept of learning environment is considered by many authors with different reflection on essence of completeness.

The goal is to distinguish features of the process of perception and clarification of specific principles in computer-oriented learning environment.

Presenting main material. The invention of textbooks and computers with text-based interface was "unnatural" event. Firstly, the working field of view has narrowed significantly since the solid angle of a text page or screen text display is much smaller than physiological view. Secondly, speed of information processing significantly reduced because the visual analyzer, created by evolution for quick perception of huge amounts of information stored in the wide field of view, the instant selection of the most important information and fast decision forcibly switched to artificially slow and therefore inefficient mode, inevitably when reading the text line. Thirdly, while reading text, an undesirable deviation appears in the distribution of load between two visual subsystems - central and peripheral, resulting in weakened role of the latter one. Peripheral central system is more important because "for an adequate understanding of the visual scene the large-capacity of instantaneous coverage of relations between objects is more important, than opportunity for a fine foveal analysis of individual parts". From clinical practice it is known that the injury of the peripheral areas of the field of view an intact foveal (central) area is equivalent to blindness (Rashkevych, 2011, p.151-154). Thus, the use of textbooks and computers with a text interface leads to the artificial shutdown of biggest part of peripheral vision and is equivalent to partial "blindness" and the exclusion of a large part of the brain, and as result - enormous reserves of human intelligence are not being utilized. Perhaps for this reason modern software have a graphical student interface (Yefimenko,2002, p.136).

Experienced teacher, who aims to instill students the methods of scientific knowledge about the subject, always includes a mechanism of visual thinking, using groundbreaking educational materials (Bykov, 2009. p.24-49). This naturally matches with all others, because according to $\mathrm{M}$. Idei, "... the images that can be seen are amenable to study much easier than ephemeral images that are perceived by auditory or sensory systems". In this case a complete image is adequately considered only when student builds a connection between the elements, i.e. forms a logical chain of reasoning-knowledge (Yevdokymov, 1997. p. 123-129).

An ability of a teacher to present visual information and find images that can adequately convey the essential features of the subject, is acting as an essential element. In some situations, drawing, showing even a separate environmental case, can carry information, a statement, which would require considerable time to form this concept in an accessible form for students. "Any uniform of the airliner steward, waiter, railway employee or the police man - a sign that shows us the diversity of the person relationships with us and society, the sign is very precise, clear and thrifty in the sense of huge amount of information contained therein" (Morze, 2012. p.24-27). Teacher inevitably tends to reinforce with illustrations the formation of beliefs that serve as signals to the conscious actions targeted at knowledge. The use of computer-based education environment can significantly increase the effectiveness of "inclusion" of mechanisms of visual thinking in the educational process.

The property, which is inherent in visual media allows, using special organization and design, naturally affect different aspects of thinking: abstract and logical. However, this property should be properly implemented so that the meaning of concepts that breed information was clear, visible.

In computer-oriented education environment "interactive visualization" is implemented, allowing to see something that is not always possible in real life, even using the most sensitive and accurate devices. Moreover, with representation in the form of computer objects can make different actions not only to explore their static image but the dynamics of development in different conditions. A computer allows both distinguishing the main patterns 
of the studied object or phenomenon, and considering it in detail. Various forms of representation of the object may change each other by the students will or with the program command, alternately or simultaneously using creative, analytical and verbal presentation. This allows condensing the information from the research object, and expanding it. Processes modeled by computer may be different in form and content, to treat the physical, social, historical, environmental and other processes. Visibility provided by the computer suggests a powerful new tool for learning - computer graphics, which represents not only knowledge in the form of images, pictures and text, but can visualize the human knowledge that cannot be found in text descriptions, or require higher level of abstraction. The process of perception in computer-oriented learning environment is accelerated and simplified by a new, speechless but functional environment of communication, like the light around us. The exchange of information is in the form of models (similar to that instead of the book to read, the current sample of a technical device or idea, that is functioning clearly, formulas or theorems are sent). The information in this case and it is immediately perceived as an image. There is a simulation sharing objects between users, though in reality, designed information is being transmitted over information channels. It is interpreted by "intelligence" of the end device. In this case, all the conveniences of transfer of information are saved (unlimited reproduction, high speed, low cost and energy) enhancing the ergonomics of the information.

In the work devoted to the study with the use computer-based educational environment, specific principles are introduced and substantiated: interactivity; virtualization; integrity and unity; openness and flexibility of training; creativity; free choice of received information; identifying; reproduction. Comprehensive analysis shows that these are not new principles, but a manifestation of features of computer-based learning environment in the implementation of the basic principles of teaching (Kasatkin, 2011. p. 330-336).

Researchers are mainly go through the creation of a special system that reflects the specific environment or developing principles to particular media, which results in dozens of substantiated specific principles.

Computer-oriented education environment allows us to define both "total" and "partial" in each element of the structure. This is due to the fact that in given environment student can be considered as a subject of a study, not as an object, while a computer is considered as a teaching tool.

Let us define the specific nature of principles to ensure the effective functioning of the computer-based education environment (initial knowledge, interactivity, virtualization, integrity and unity, openness and flexibility training, creative nature of free choice of the information received, identification, reproduction, "island" of information, interoperability).

The principle of initial knowledge implies an entry-level of knowledge of potential education services consumer, their hardware and technical skills. For example, during training within the network model is not only necessary to have a computer with Internet access, but have minimal skills working online. Therefore, to study effectively, prior computer training is required.

The principle of interactivity reflects a pattern of the students - teachers contact, using the information technology tools, as well as students' interaction. Typically, in the computerbased education environment, the intensity of the exchange of information among students is better than among students and teachers. Therefore, in order to implement this principle, for example, during computer conferencing, it is necessary to share emails to all participants of the educational process. Interactivity reflects the opportunity to interact between students who are subscribed to educational resource. Obviously, polysensority, adaptability and interactivity are achieved by using a computer technology.

The principle of interactivity in communication with the information reveals a key requirement of the didactics of distance learning, according to which the student has a real 
feel for the presence of teacher training. Measures are widely used for this purpose such as dialogue, discussions, teleconferencing and others.

The principle of virtualization of structured system information actively uses various symbols, videos, computer tutorials and interactive techniques. Construction of virtual resources and their usage is one of main of tasks for any computer-oriented learning environment. This principle allows presenting the structure of the system in a defined set of processes and distributors of resources (monitors) and uses a centralized resource allocation scheme. The most natural and complete expression of the concept of virtuality is the concept of the virtual machine.

In fact any learning environment has allocating resources that are organized according to defined processes management rules, hiding from teachers and students real hardware and other resources, replacing them with some abstraction. As a result, students see and use the virtual machine as a device that can perceive their programs written in the defined programming language and publish the results. In this representation student is not interested in the actual configuration of the computer system, how effectively its components and subsystems are being used. He thinks and works with the machine in terms of language and the resources available to him within the computer-based learning environment.

The principle of the integrity and unity is actually a completeness of computer-based learning environment - the structure where everything is interconnected and everything is subordinated to a single goal, idea. This relation can be found in structural and logical scheme of operation of mentioned environment, in a harmonious order and unity of content and form.

The principle of openness and flexibility training is expressed in "soft" restrictions on age, initial educational qualifications, starting control measures on the possibility of training in the form of interviews, exams and other tests. The experience of foreign educational institutions of computer-oriented learning (the British and Spanish Open University, and others.) and also domestic ones, says that this fact does not reduce the quality of education, but requires additional efforts in the further individual training of a student. An important indicator of the flexibility of the educational process is absence of binding it to the distance, the time schedule for its implementation, specific educational institutions. Ideally, the latter requirement is a need of creation of a remote distributed knowledge networks for distance learning, allowing students adjusting or supplementing their educational program in the desired direction easy enough in case of absence of adequate services in the school where he studies. Herewith the preservation of informational invariant in education is required, to provide the ability to transfer knowledge from one institution to another within related or not areas.

The principle of creative nature - is in cognitive activity and solving the problems of education and self-development. Information technology requires students to be creative, action by their own and transform information from the outside world.

The principle of free choice of the information occurs with certain activities (participation in discussions, teleconferences, work with search programs, comparative analysis of information in the WWW, etc.).

The principle of identification is the need to control learning autonomy, since by the use of computer-based learning environment, more opportunities are provided for the falsification of training than, for example, full-time or part-time.

Identification of the student is part of the joint security measures. Control of independence in carrying out tests, essays and other control measures can be achieved, in addition to eye contact, through a variety of means. For example, to identify the person that passes the exam by using video-conference connection. 
The principle of self-reproduction - while working in a computer-oriented learning environment, measures are designed to increase diversity, augmentation of alternatives and opportunities. Creating healthy competition leads better selection is implemented.

The principle of "island" of information involves the development of an integrated and interconnected system of information and tools for solving problems of information and analytical support of a computer-based learning environment.

According to this principle, work in computer-oriented learning environment must begin with a few elements in some universities. Their experience can be transferred to others, considering and correcting mistakes.

The principle of interoperability (compatibility) - describes the interfaces of applications and environmental resources, and also users (students-ecologists) and components of the computer-based learning environment. Interoperability is achieved through applied educational services that support interaction on the basis of standardized interfaces, computer-based learning environments.

So, according to V. Yefimenko, the use of computer-oriented learning environment leads to a radical rethinking of the purpose, content, forms and methods of training at the new modern level. This computer-oriented learning environment has an open multivariate character; contributes to the organization, self-organization and personal development (involves coordination of all participants in the educational process information); updates the intellectual, moral, communicative possibilities of the individual, ensuring comfortable integration in society and culture (Yefimenko, 2002).

The work of a teacher in computer-oriented learning environment requires a modernization of the methodical work of the institution, and to do this, institution should develop a program of continuous improvement of professional competencies of a teaching staff in the field of ICT, use in accordance with the professional needs and abilities.

Conclusions and further research. Therefore, the implementation of computer-based learning environment enables its use as:

- educational tool;

- cognition instrument;

- telecommunication tool;

- means of personal development;

- $\quad$ effective tool for monitoring and correcting the results of training activities.

A feature of computer-based learning environment is that the pace of learning depends on the student's individuality and increases through the organization of communication between the user and information resources in real time.

The training of future specialists to use computer technologies in professional activity in our study is not an aim in itself. In further studies, the main task is to build such a learning environment where skills in using information technologies of future farmers will be similar to skills of writing, reading and basic math, which are components of key competences.

\section{REFERENCES}

Bykov, V. (2009). Innovative development of society and the modern network technologies of open education. Problems and prospects of forming a national humanitariantechnical elite:: P78 zb. nauk. Prats. №23-24 (27-28), 24-49. (in Ukrainian)

Yevdokymov, O. (1997). New pedagogical technologies of teaching students. Dys. kand.ped.nauk, 13.00.01 Kh., 312p. (in Ukrainian)

Kasatkin, D. (2011). Principles profile information and educational learning environment. Naukovyi visnyk NUBiP Ukraine, 159(2), 330-336. (in Ukrainian)

Kulyk, E. (2003). Designing ynformatsyonnoy obrazovatelnoy environment and personality Lecturer. 
http://ito.edu. №7003/1/3/1-3-2289.html (in Russian).

Morze, N. \& Glazunova, O. (2012). Methods of creating e-learning courses. Navch. Posibnyk, 247 p. (in Ukrainian)

Solso, R. (2011). Cognitive psychology. 6-e uzd, 589 p. (in Russian).

Rashkevych, Yu., Ovsiak, V., Nizolek, M. \& Petrushka, Yu. (2011). Model GUI settings by composite of uniterm. Kompiuterni nauky ta informatsiini tekhnolohii: zbirnyk naukovykh prats, 151-154 (in Russian).

Yefimenko, V. (2002). Pedagogical bases of development of the project-program the information environment of higher education institutions

http://www.ito.su/2002/IV/IV-0-136.html. (in Russian). 